Please do not remove this page

RMIT

UNIVERSITY

\title{
A pinch of ethics and a soupçon of home cooking: Soft-selling supermarkets on food television
}

Lewis, Tania; Phillipov, Michelle

https://researchrepository.rmit.edu.au/esploro/outputs/9921862533701341/filesAndLinks?institution=61RMIT_INST\&index=null

Lewis, T., \& Phillipov, M. (2015). A pinch of ethics and a soupçon of home cooking: Soft-selling supermarkets on food television. In Food, Media and Contemporary Culture: The Edible Image (pp. 105-124). Palgrave Macmillan.

https://researchrepository.rmit.edu.au/discovery/fulldisplay/alma9921862533701341/61RMIT_INST:Resea rchRepository

Document Version: Accepted Manuscript

Repository homepage: https://researchrepository.rmit.edu.au

(C) Peri Bradley 2015 Individual chapters (c) Respective authors 2015

Downloaded On 2023/04/27 00:23:57 +1000 
Thank you for downloading this document from the RMIT Research Repository.

The RMIT Research Repository is an open access database showcasing the research outputs of RMIT University researchers.

RMIT Research Repository: http://researchbank.rmit.edu.au/

\section{Citation:}

Lewis, T and Phillipov, M 2015, 'A pinch of ethics and a soupçon of home cooking: Soft-selling supermarkets on food television' in Peri Bradley (ed.) Food, Media and Contemporary Culture: The Edible Image, Palgrave Macmillan, London, United Kingdom, pp. 105-124.

See this record in the RMIT Research Repository at:

https://researchbank.rmit.edu.au/view/rmit:34386

Version: Accepted Manuscript

Copyright Statement: (c) 2015

Link to Published Version:

http://trove.nla.gov.au/version/212894374 


\section{A Pinch of Ethics and a Soupçon of Home Cooking: Soft-Selling Supermarkets on Food Television}

Tania Lewis and Michelle Phillipov

On 27 August 2013, Australian commercial broadcaster Network Ten screened a new reality show, Recipe to Riches, in a primetime slot. Based on a Canadian format of the same name, the show sees contestants_ordinary people with no formal training or food credentials — competing for the prize of having their homemade recipes recognised as worthy of being top-selling supermarket products. This chapter discusses the Australian version of this somewhat unusual reality show, situating the rise of the format in the broader contexts of the increasing politicization and scrutiny of food production and provenance as well as the role of agri-business and supermarket players in Australia and internationally. Reality-based food shows like MasterChef Australia (Network Ten 2009-) have proved to be highly successful commercial ventures, integrating 'below-the-line’ advertising and commodities seamlessly into their format structure and content. Sponsored by major Australian supermarket chain, Woolworths, Recipe to Riches takes this commercial logic considerably further. Turning the recipes of ordinary Australians into mass products through a large-scale 'batch up’ process in a (purportedly) commercial kitchen, the show's narrative involves developing a branding strategy and a product launch, finally resulting in its temporary placement on Woolworth's shelves, at which point viewers get to 'vote' for their favourite product by buying it in-store or online.

While the show's commercial logic is clearly linked, at least in part, to increasing product sales, as one of only two dominant players in the Australian supermarket sector (the Coles supermarket chain is the other), we argue that Recipe to Riches is primarily about boosting the image of supermarkets in the community. In recent years, supermarkets in Australia have come under attack for their perceived poor treatment of farmers, suppliers and local producers, while questions of animal welfare have resulted in mounting pressure on the two majors to stock more 'ethical' products. At the same time, 'foodie' culture and cooking at home have undergone something of a renaissance, with celebrity chefs like Jamie Oliver (who is highly popular in Australia) encouraging people to cook from scratch rather than eat 
processed foods, and home grown chef-personalities like Stephanie Alexander and her Kitchen Garden Foundation teaching a new generation of foodies in schools across Australia how to grow, harvest and prepare healthy food. This artisanal turn has also occurred against the backdrop of an increasing critical focus on the industrialisation of food in mainstream media. In this context, we argue that Recipe to Riches can be seen as attempting to reconfigure the public image of supermarkets. Describing itself as 'lifting the lid' on supermarket products, the show borrows from the 'behind the scenes' conventions of critical relevatory TV shows and documentaries exposing the practices of food processing and industrial agri-business, such as Food Inc. (2008), Food Factory (BBC One 2012), Jamie’s Fowl Dinners (Channel 4 2008), Jamie Oliver's Food Revolution (ABC 2010), Hugh's Chicken Run (Channel 4 2008). This paper will discuss the ways in which Recipe to Riches reworks the critical logic of such shows for its own ends by attempting to gloss over the industrial realities behind Woolworth's processed food products and to link supermarket products with the homes, recipes and artisanal cooking skills of ordinary Australians and with the ethical credentials of celebrity chefs. Locating the show within the broader context of heightened mainstream awareness of, and concerns about, how we produce, source and buy our food, we discuss the growing role of shows like Recipe to Riches and non-state actors like supermarkets and celebrity chefs in attempting to intervene in and shape normative discourses and practices around food ethics and politics.

Before discussing Woolworths' strategic use of Recipe to Riches as a vehicle to appropriate and re-figure questions of food production and provenance, the paper provides a broad contextual background to the recent foray of supermarkets into the televisual space. Accordingly, the chapter is structured as follows: it begins by briefly mapping the growing media focus on questions of where our food is sourced and how it is produced. It then outlines the recent media critiques of supermarkets, focusing on contemporary debates in Australia. This is followed by an review of some of the ways supermarkets have attempted to respond to these critiques before moving on to an indepth examination of Recipe to Riches and the way in which it attempts to intervene in, and reshape the terms of, debates around industrialised food production and lengthened commodity chains.

\section{Food Politics on Television}


While Recipe to Riches can, on the surface, be read as a show that promotes personal branding and competitive individualism (an analytic frame commonly used to critique reality game shows), our key argument here is that it also does complex cultural labour for supermarkets in the areas of food ethics and politics. This is a theme that has become particularly prominent in Australia, with growing media attention being paid to questions of ethical consumption and the supermarketisation of food chains. In recent years, questions of the ethics and sustainability of food production, sourcing and consumption have become increasingly prominent in wealthy capitalist nations around the world (Barnett et al. 2005a; Coff 2006; Goodman et al. 2010; Lewis and Potter 2011). An important factor behind this has been a growing critical interest in the ethics of food production and consumption and an associated critique of agribusiness practices within popular media, publishing and the press. US food writer Michael Pollan's hugely popular books are one such example of the recent mainstreaming of food politics. In his bestselling book In Defence of Food: An Eater's Manifesto (2008) he argues that our food systems have been taken over by science and calls for a re-connection with 'real', unprocessed food, while in the widely read The Omnivore's Dilemma (2006) he traces the steps in various food chains, including food produced by large agri-business, raising questions about the negative health and environmental impacts of industrialised food systems. Another key example of mounting public interest in such questions has been the widespread international popularity and impact of the 2008 documentary Food Inc., a slicklymade and entertaining exposé of the power of big agri-business in the US, where profit-driven, environmentally damaging industrial practices are shown to have impacted on every aspect of the food chain from seed propagation to farming to supermarket sourcing.

While critical bestsellers and popular documentaries have contributed to the rise of widespread debates around food issues, perhaps the most influential media player in this space has been television. Over the past ten years, food television and celebrity chefs, particularly in the UK, have played a central role in everyday primetime media coverage of food production and consumption, giving heightened visibility to a range of food issues from animal welfare and health and wellbeing to the impacts of industrialised food production and questions of food sourcing and sustainability. For instance, in the UK, the efforts of programmes such as Jamie Oliver's Jamie's Fowl 
Dinners and Hugh's Chicken Run, hosted by chef and TV personality Hugh FearnleyWhittingstall, to raise media awareness about the conditions in which chickens are raised commercially for eggs and meat have been linked to significant growth in the numbers of free-range products available in British supermarkets as well as decreased consumer demand for factory-farmed products (Hickman 2008). Oliver has been especially adept at exploiting the emotional power of the pop doc/reality format in order to foreground a range of social and political issues around food consumption and production. Central themes of the popular UK series Jamie's School Dinners, for instance, included Oliver's often-caustic critiques of commercial food culture and the negative impacts on children of diets dominated by fast and pre-prepared foods. Jamie’s bête noire, the 'turkey twizzler', came under particular criticism, generating so much negative publicity as to be subsequently withdrawn from sale in UK supermarkets (Lewis 2014).

Australia has also had something of an 'ethical' turn on food television, though it has not had quite the same broad mainstream exposure as in the UK. Focused mainly on middle class 'foodies', it has primarily manifested itself in the soft, 'lifestyled' subgenre of food tourism or 'Tour-Educative' TV (Strange 1998) rather than in more confrontational reality pop docs like those produced in the UK (de Solier 2005; Lewis 2008). Recent examples include Gourmet Farmer (launched in 2010 on the niche public broadcaster SBS), a 'lifestyle migration’ show about a city dweller who moves to the country to learn how to live ethically and sustainably (but in gourmet style) from and on the land, and Paddock to Plate (first broadcast in 2013 on Foxtel's Lifestyle channel), a Tour-Educative program featuring well known Australian chef and restaurateur Matt Moran who travels around rural Australia discovering places renowned for their local food. ${ }^{1}$

In contrast to the everyday experience of food purchasing, preparation and consumption in today's convenience-oriented culture, these shows promulgate an essentially 'slow food' philosophy emphasising local, traditional food sourced and prepared in ways that are connected to the land. The food tourism genre can thus be seen to present a significant counter-discourse to supermarketised foodways and industrial agriculture, inviting viewers to think and buy locally, and to re-connect 
their own food practices to family, community, and lifestyles that emphasize social ties and connections.

As Lewis argues elsewhere, the lifestyling of cookery shows can also be seen to offer an alternative to processes of culinary "rationalization”, from the globalization and industrialization of food production and consumption to the growing scientisation of food and eating as sites of controlled consumption. (Lewis 2008)

The local, highly successful iteration of MasterChef, which has been airing on commercial television in Australia since 2009, also focuses on the joys of rediscovering long-lost family traditions of food preparation and routinely inserts commentary about food provenance - though the show's heavy emphasis on product placement and integrated advertising (it has multiple sponsors, including Coles supermarket) have largely seen concerns of 'ethical' purchasing and consumption pushed to the side. Increasingly, however, as discussed below, various concerns about the corporatisation of food production and retail have begun to find their way on to the public agenda in Australia, forcing supermarkets to intervene in the space of food ethics and politics.

\section{Of Milk and Meat: Scrutinising Supermarkets}

Australia's food retail market is dominated to an unusual extent by just two supermarket 'majors', Coles and Woolworths. While the exact figures of Coles' and Woolworths' market share are open to debate, according to one authoritative analysis conducted prior to Australia's 2013 federal election (during which the concentration of supermarket power was pushed as an election issue by three prominent independent MPs (see Martin 2013), these two vertically integrated companies share somewhere between $70-80 \%$ of the country's grocery business, or between $55-60 \%$ when fresh produce is included in the calculation (King 2013). While this situation has been deemed 'workably competitive' following a 2008 investigation by the competition regulator, the Australian Competition and Consumer Commission (ACCC), there has growing public debate about the power of this effective duopoly and the increasing role and impact of globalised agrifood production networks in Australia (see Richards et al. 2012). 
Public concern about supermarket dominance has also intensified in recent years as a result of series of food scandals, each of which received extensive coverage in the Australian press. These include the high profile 'price wars' between Coles and Woolworths over staple items such as bread and milk. On Australia Day, 26 January, in 2011, Coles slashed the price of its private-label milk causing Woolworth and other retailers to follow suit. Cutting milk prices to well below cost placed significant pressure on dairy farmers and processors (Cook 2012). While the supermarkets emphasised the consumer's sovereign 'right' to low prices and 'choice', the media highlighted the plight of farmers while, at the same time, rumours of anti-competitive behaviour, coercion and bullying of suppliers by the large retailers began to emerge. ${ }^{2}$ The incident generated unprecedented public interest and put the spotlight on the fraught power relationships between local food producers, suppliers and retailers in a market increasingly dominated by global agri-business and international retail chains.

In May 2011, not long after the 'milk wars' affair was first broken by the media, the ABC's Four Corners programme, a highly regarded long-running weekly current affairs show on Australia's public broadcaster, aired footage of numerous acts of cruelty being inflicted on live Australian cattle exported to Indonesian abattoirs for slaughter (Ferguson 2011). The subsequent public outcry saw the government announcing, a week later, that it would ban all live cattle exports to Indonesia until sufficient animal welfare standards could be ensured (Zappone 2011).

While the poor treatment of live meat cattle did not directly impact on Australian supermarkets (they source their fresh meat locally), the substantial media coverage that both these incidents received saw a dramatic increase in the public awareness of issues around food sourcing and 'ethical' produce in Australia. As a result, it is now commonplace for the mainstream media in Australia to run stories related to food production, sourcing and provenance. Given their dominance of the food retail market, it is not surprising that food-related stories are often focused on supermarkets-from articles rating Coles and Woolworths on their claims to strive for sustainable palm oil usage (Davidson 2013) to scrutiny of their recent declarations that they are moving towards stocking solely 'free range' eggs and chicken (Fyfe and Millar 2013; Whyte 2013). 
The particularities of the Australian Coles/Woolworths duopoly, combined with the broader critiques of supermarket food that are circulating both domestically and globally, has contributed to declining consumer trust in the major supermarkets (Richards et al. 2011). A 2012 survey, for example, found that $72 \%$ of consumers distrusted Coles and Woolworths (McIntyre 2012). Declining consumer trust has also contributed to the growth in markets for alternative retailing models, such as farmers' markets, organic box schemes, direct online retail, and farm gate sales, which are each seen as offering not only a more direct connection to the source of one's food but a fairer, more equitable, more sustainable relationship between producer and consumer (Guthrie et al. 2006; Fielke and Bardsley 2012).

In response, supermarkets have sought to re-engage consumer trust and boost their image in the community via a range of strategies, including introducing 'ethical' food lines into their grocery repertoire, making a significant investment in high visibility TV formats such as Recipe to Riches and Masterchef Australia, and mobilising extensive re-branding campaigns. As Lewis and Huber (2015) note, in two 'ethical' branding campaigns recently mounted by Woolworths and Coles, the supermarkets sought to leverage the associations between celebrity chefs, 'good' food and ethical eating by partnering, in the case of Woolworths, with global food icon, Jamie Oliver, and in the case of Coles, with local-chef-made-good, Curtis Stone, as the 'faces' of their ethical campaigns. The 'ethical capital' (Lewis and Huber 2015) of these celebrity chefs was deployed to signify a commitment to issues such as animal welfare (an association strengthened by both supermarkets also linking their brands to key animal welfare groups), and to 'authentic', local and ethical modes of food production as means of re-authenticating the role of supermarkets within the Australian grocery sector.

Woolworths' partnership with Oliver began in October 2013, the announcement of which also coincided with a commitment from the supermarket chain to phase out stocking 'cage' eggs and phase in RSPCA-approved chicken by $2018 .{ }^{3}$ In brokering this partnership, Woolworths astutely aligned itself with one of the best-known international advocates for home cooking, healthy cuisine, and the virtues of local and ethical produce. By associating itself with Oliver's trustworthy persona, wholesome 
family-oriented lifestyle, familiar warmth and bonhomie, Woolworths was able to boost its public image with relatively little labour on behalf of their marketers (Lewis 2010).

Likewise, Coles has sought to reengineer its image through associations with key community actors who are perceived as trustworthy and authentic, using local celebrity chef Curtis Stone, who has endorsed the supermarket chain since 2008, to front its 2013 ethical Christmas food campaign, which emphasised responsibly sourced local produce with a traceable provenance. In January 2014, Coles announced that all its 'own brand' chicken would be RSPCA approved, accompanied by another series of TV commercials featuring Curtis Stone and tagged 'Raised Better, Tastes Better'. This built upon Coles’ 'Helping Australia Grow’ campaign, launched in 2013 and also fronted by Stone, which featured idyllic rural imagery and endorsements from the satisfied 'Aussie farmers' who supply to Coles.

Alongside advertising campaigns featuring celebrity chefs, happy chickens and happy farmers, the retail giants have paired these campaigns with a redesign of stores. Coles and Woolworths have adopted in-store design and labelling strategies that seek to replicate a number of the conventions of farmers' market shopping experiences. This has included remodelling store layouts in ways that divide fresh food shopping into separate specialist 'zones' (bakery, butcher, deli), the effect of which is to 'blur...the division between corporatized food retail and a "market place” atmosphere with separate purveyors of different goods' (Keith 2012). Labels and product packaging in the fresh food sections also increasingly includes QR (Quick Response) codes that enable smartphone users to scan the codes to put a 'face' to the farmer/producer and enjoy virtual 'meet the farmer/producer' experiences.

\section{Recipe to Riches: From Aussie Homes to the Supermarket Shelf}

Another key way in which supermarkets have sought to reconnect with consumers and authenticate their brand identities in the context of industrialised foodways is through sponsoring food television. With food programming increasingly dominating primetime schedules, sponsorship and advertising strategies have become more sophisticated, employing a range of 'integrated' advertising techniques, including product placement, integration of brands in storylines, branded tie-ins, and other kinds 
of branded programme content (Spurgeon 2013). Both MasterChef Australia and its main ratings rival, My Kitchen Rules, feature the integrated advertising of its major sponsor, Coles. This has proven to be very successful, with the supermarket chain reporting sales surges of particular ingredients, such as ling fish and lambs brains, after they feature on the television shows (Sinclair 2010). In fact, these sponsorship arrangements have been so effective that they have been credited with helping Coles to ‘close the gap’ with Woolworths (Janda 2010)

Woolworths' relationship with Recipe to Riches, however, has been described as taking 'sponsor integration and product placement to new levels' (Jackson 2013). Woolworths operates as a thoroughgoing editorial collaborator on Recipe to Riches. The supermarket chain plays a significant role in the decision-making involved in the show, and as well as featuring Woolworths Director of Customer Experience, Jess Gill, as part of the judging panel, Woolworths also reserves the right to veto contestants during the audition stages of the competition.

Unlike MasterChef Australia and My Kitchen Rules, Recipe to Riches’ ratings have been lacklustre overall but the programme has nonetheless been seen as a success for Woolworths (Jackson 2013). This is because the show has been credited with improving Woolworths’ customer loyalty—it has reportedly contributed to both a growth in new customers and a re-engagement of lapsed ones-as well as with generating increased sales and a positive 'halo effect' for other major supermarket brands, including the Woolworths Select range, for which the show has helped boost brand associations of authenticity and quality (Greenblat 2013). If the aim of Woolworths' involvement with Recipe to Riches was to get more people through its doors and thinking positively not just about the products featured on the television show but also about supermarket brands more broadly, then it is a model of sponsorship that appears to be working for the supermarket chain.

A key element of the success of Recipe to Riches is the way in which the show domesticates supermarkets, working hard to link supermarket products not to mass industrial processes but to the everyday practices of ordinary householders. Featuring a range of ordinary Australians competing to have their homemade recipes chosen to become supermarket products, the show takes pains to emphasise the domestic, 
familial settings out of which the various recipes featured on the show have emerged. Though the show is framed as revealing the 'behind the scenes' journey of products from recipe to supermarket shelf, it ultimately divulges very little about the actual practices of product development and food manufacturing and instead focuses on the people, personalities and 'stories' behind the recipes. Thus, while the format plays with a number of the conventions of critical revelatory television shows and documentaries to purportedly grant viewers access to a range of 'trade secrets' about supermarket food production, this aspect of the show is, at best, perfunctory.

For example, the filming of contestants during the 'batch up' round of the competition, where they are asked to reproduce their home recipes in 'commercial quantities' to determine their adaptability to large-scale production, reveals little about the actual process of mass industrial food processing. The batch up takes place not in an industrial kitchen, but in the kitchen of a Sydney catering college, while the 'industrial' equipment used extends only to the mixers, kettles and brat pans of the scale used by caterers and restaurant kitchens, not those used by food manufacturers. In fact, much of the preparation looks like what contestants would normally do at home, except in much larger quantities - an element that often produces amusing if predictable results while providing some much-needed narrative tension. Muffin cases and cake tins are filled individually, while ingredients like chillies, dates and apple pieces are finely chopped by hand. On the most recent series, one contestant spent a considerable portion of his limited preparation time individually zesting and juicing 140 lemons, while another painstakingly made apple sauce by puréeing apples in multiple batches in a regular home blender.

While the batch up process is obviously a far cry from what goes on in food manufacturing facilities, this implicit linking of domestic cookery practices, the personal stories behind homemade recipes and supermarket goods arguably does significant ideological work for supermarkets, working to contest broader concerns about supermarket food, global agribusiness and major food manufacturers. A key feature here is the way in which Recipe to Riches locates contestants' laborious preparation of 'handmade' offerings within discourses of the artisanal. For example, A.J. Mills, series two finalist in the baking category, tells us that her 'cookies are made with love', as demonstrated by her efforts to source high quality ingredients 
(she specifically mentions best quality chocolate and free range eggs) and by the extra time she devotes to preparing the brown butter for her cookie dough ('the brown butter gives my cookies a really nutty caramelised flavour,' she says). Consequently, contestants’ products are primarily shown not as something made in factories (although they certainly are when they end up on Woolworths' shelves), but as something made by hand with skill, care and attention and with carefully selected ingredients of known provenance.

In doing so, Recipe to Riches appropriates and reframes discourses of the alternative food movements that seek to offer a corrective to the alienating forces of contemporary industrial food production by reconnecting consumers with the sources of their food. The show thus conflates the handmade and artisanal with the mass produced in a way that not only (and somewhat paradoxically, given the stated purpose of the show) obscures the real conditions through which supermarket products are produced, but also implicitly shores up Woolworths' ethical credentials. On Recipe to Riches, supermarket products never emerge from an anonymous production line or are designed primarily with profit in mind; supermarket products are instead carefully crafted and always made with 'love'. Furthermore, Michael Pollan's (2008) concern that supermarkets are today are increasingly filled with 'foodish products' containing ingredients that ‘your ancestors simply wouldn’t recognise as food' appears to be completely unfounded on Recipe to Riches. According to the ingredients lists posted on the screen at regular intervals throughout each episode, A.J.'s cookies are made only with butter, brown sugar, chocolate, eggs, plain flour and sour cherries. Similarly, rather than containing a panoply of ingredients that we would not recognise as food, Michael Cainero’s sausages, the product that ultimately won the competition, are listed as containing only pork mince, dried apple, apple purée and cinnamon.

As a result, many of the criticisms and concerns about processed foods-that we don't really know what is in them, that they have negative impacts on our health, that they promote unhealthy and unsustainable ways of eating-are turned on their head by Recipe to Riches. Michael explains that his sausages were developed because his daughter's food allergies necessitated that he 'know exactly what goes into [his] food', resulting in a 'real healthy, real nice sausage' based around whole ingredients. 
The additional preservatives, thickeners, stabilisers and other additives that are unnecessary for homemade dishes, but which are essential for ensuring the shelf life, texture and appearance of mass-produced products designed to be shipped around the country are simply invisible on Recipe to Riches. Even the 'Show to Shelves' segments that appear as online extras on the Recipe to Riches website and Facebook page and which feature commentary from Woolworths' food technologist and Product Development Manager, Jane Rodway, do not include any additional information about the manufacturing process beyond what was provided on the show itself. With only a few seconds of factory footage at the end of each episode and with only brief discussions of the manufacturing process during the series finale, it would easy to assume that mass-produced supermarket products are made in essentially the same way and using the same ingredients as home-cooked recipes.

This is because the purpose of providing details about the manufacture of Recipe to Riches' products is less to offer viewers real insight into the food production process and more to reinforce a single core message about the lengths Woolworths went to faithfully replicate the taste, quality and integrity of contestants' original homeproduced recipes. For instance, the finale introduces the different factories and food manufacturing companies that produced the products, as well as discussing the various challenges and difficulties involved in bringing each product to market primarily in order to outline the obstacles that were overcome to preserve the 'homemade' qualities of each contestant's product. When A.J.'s original cookie dough recipe was found to be too soft to pass through the mechanised cookie cutter, the dough was chilled to a colder temperature to produce a firmer texture. When Michael's sausages were discovered to only have a shelf life of 14 days, factories on both the east and west coasts of Australia were contracted to produce them so that they could be distributed more quickly to Woolworths stores across the country. When factory machinery was unable to replicate the techniques used to produce Sahar Awdi's date cake (Sahar would prick each cake all over with a fork to enable the toffee sauce to soak into the crumb), a new tool was custom-designed to allow factory staff to spike each cake by hand. The result is an heroic narrative about Woolworths' commitment to maintaining product authenticity. 
As part of this, contestants were frequently called upon to endorse Woolworths' effort to ensure the best outcome for their products. For example, when Michael was asked what he thought of the 'lengths that the supermarket went to get your products on the shelves', he responded: 'Amazing... I'm extremely happy with all the people that work behind the scenes'. Darcy Taylor said that he was 'really happy—over the moon' when asked how he felt about 'how much care and attention went into making [his] choc bombs'. When asked what she thought about 'how much effort has gone into making sure your product was fresh and not frozen', Zoe Wombell praised Woolworths for preserving the integrity of her sausage roll recipe. '[I'm] so pleased,' she said, 'because I expected the taste to be so different from what I cooked. I was just over the moon that it still had that French puff about it and it just tasted like a good hearty sausage roll’ (series 2, episode 8).

Perhaps in response to criticisms from last years' contestants that they were not consulted about (nor were they happy with) modifications made to their original recipes during the manufacturing stage, the finale was at pains to emphasise the 'collaborative' relationship between Woolworths and the Recipe to Riches contestants in the production of their recipes. For example, when it was discovered that the navy and pinto beans used in Ricardo Escalon's original recipe for Latin beans did not hold their shape well during the cooking and reheating processes, these were substituted with navy, borlotti and kidney beans. Ricardo was not only consulted on all alterations, he also felt that the modified recipe resulted in the 'best Latin beans' he had tasted. When A.J.'s cookie dough was modified to accommodate the production machinery, the finished product was returned not only to the Woolworths' Sensory Kitchen for a final taste test, but also to A.J. herself: as judge Carolyn Creswell put it, 'once all the boxes were ticked and the contestants were happy with the quality, the product was ready to go' (series 2, episode 8).

This image of Woolworths as a benevolent collaborator working with contestants to protect the integrity of their product whatever the 'lengths' and 'effort' required provides a counterpoint to criticisms of Woolworths' treatment of farmers and suppliers. The negative news coverage of supermarkets' exploitation of their asymmetrical power relationships with suppliers is instead contrasted with images of food manufacturers delighted to manufacture products to the tight deadlines and 
narrow specifications required and contestants who are, without exception, pleased with the final result. While this perhaps reflects the particularities of the products designed for the Recipe to Riches show_-attempting to replicate home recipes by any means tends not to be part of the usual practices of product development-it is also implied that the efforts made for the Recipe to Riches contestants are typical of Woolworths' practices more generally and were not unique to the products created for the show. As Woolworths Director of Customer Experience, Jess Gill says at the commencement of the finale, 'I'm really, really excited tonight, because everybody will be able to see the effort that goes to bringing our products to our shelves' - not just ‘these particular products’ but ‘our products’ more broadly (series 2, episode 8).

This works to obfuscate the fact that the Recipe to Riches products are not typical of the foods normally sold within, and manufactured for, supermarkets. Creswell alluded to this during the series two finale when she gushed that Sahar's date cake was 'restaurant quality' and so 'to get something like that from the supermarket is unbelievable’: its quality was achieved precisely because it did not obey the usual 'rules' of supermarket food production. Its manufacture was time consuming and laborious and, like most of the products associated with the show, its price was comparatively high for a supermarket item. Without the promotional vehicle of a television show, it is unlikely that it would be viable as a supermarket product, thus contradicting the very foundations of the show itself.

\section{Placing Supermarkets}

Supermarkets have been viewed as 'non-places'-generic spaces with little sense of connection to or engagement with social and community life (Auge 1995). As food retailers, they also offer an experience of food that is disconnected from seasonality and the realities of local farming, where ‘fresh' produce is available all year regardless of fluctuations in weather or the ability of local farmers to deliver consistent product in volume. And yet shopping at the supermarket is also a local experience, with outlets typically being 'around the corner' or 'down the road', employing local people and impacting communities in a variety of ways (see Dixon and Isaacs 2013; Humphery 2008). One of the functions of both supermarkets' celebrity chef-driven campaigns and media-based re-branding exercises has been to attempt to re-integrate the local back into the supermarket, to emplace and 'story' 
food, ironically often borrowing from the conventions of artisanal and alternative food discourses.

In a much-quoted article, David Goodman (2003) describes a 'quality "turn”' in alternative food practices in which the characteristics of 'embeddedness', 'trust' and 'place' intersect to create a renewed interest in place-based, sustainable, sociallyembedded food products and systems that seek to both wrest control from corporate agribusiness and resist the dis-embedding forces of globalization. The stories of the Recipe to Riches contestants mirror many of the priorities of this quality 'turn': to know where food comes from, to find an alternative to the anonymity of mass produced food, to use food as a vehicle for 'connection'. In a number of the show's introductory sequences, contestants are filmed working in their vegetable gardens, picking fruit from their fruit trees, and collecting eggs from their backyard chickens. For these contestants, a commitment to producing their own food is often stated as a direct influence on the development of their product recipes. For example, Maria Malpass' recipe for eggplant chutney came about as the result of a produce surplus in her vegetable garden. Katie Zamyical's commitment to growing her own food inspired her to only use top quality ingredients in her cooking. As she put it:

My brownies are definitely for chocolate lovers. I love the story of where food's come from, so for me, the fact that that praline is made in copper pots in France always thrills me... I love the experience of food because I think it brings people together...We place a great importance on the food that we eat and what goes into our bodies. That's why we love growing our own food, and that's I guess helped in changing my recipe for the brownie to get the best quality ingredients I can. (series 2, episode 1)

Community gardening and growing one's own produce increasingly serve as symbols of resistance to the hegemony of global agribusiness and corporate retail. For UK celebrity foodie Hugh Fearnley-Whittingstall, a high profile proponent of this position, growing one's own food is essential for 'reconnect[ing]' with sights, smells and tastes of 'real' food now that 'so much of what we eat comes wrapped in plastic from the supermarket'. ${ }^{4}$ This emphasis on connection is especially evident in Katie's story, where she explicitly links backyard and artisan food production, the provenance of ingredients and the notion of food as a conduit for relationship-building to the 
quality of her 'product'. Although Katie’s brownies are ultimately viewed as commercially unviable due to her use of expensive French praline, the fact that she is the first contestant introduced in the first episode of series two enables her to operate as a framing device for the show through which 'embedded', 'connected' and 'emplaced' food is established not as an alternative to supermarket food but as fundamentally compatible with it. Similarly, A.J.'s comments that her biscuits are 'made with love' also links themes of quality, provenance and a 'connection' with one's food. In the logic of Recipe to Riches, this exists not in opposition to supermarket food but as something that can be purchased from the supermarket as part of a wide range of other products, highlighting, as Harriet Friedmann (2005) would argue, the extraordinary ability of dominant systems to appropriate activist discourses and utilise them within new marketing strategies.

An emphasis on connection and the stories of products is also central to the branding processes used on the show. The products on the show are, for the most part, packaged and marketed with an emphasis on connecting the recipes to their 'makers': Sav’s Kebabs, Michael 'King of Sausages’ (complete with an image of contestant Michael wearing a crown), Darcy’s Choc Bombs and Ricardo’s Ranchero Beans are some of the recipes turned into 'products' in series two. Much like the advertising strategy of putting a 'face' to the farmers who supply to the major supermarkets, Recipe to Riches similarly puts a 'face' to the production of processed foods. In part this is about the self-branding and personal transformation often central to the narrative drive of reality game show formats - that is, viewers are invited not just to support new food products, but also to invest in the 'dreams' and personal journeys of the contestants. In the context of Recipe to Riches' concerns with restoring the Australian community's trust in, and connection to, their local supermarket, this foregrounding of contestants implicitly draws upon conventions common within artisanal food production where the identity of the food producer is often central to marketing the product's quality, authenticity and 'realness'.

If Recipe to Riches obscures the real conditions of food (mass) production by suggesting that food manufacturing is just like home cooking but on a grander scale, it is significant that the judge who supervises the batch up and helps to assess the recipe's ability to be reproduced in large quantities is not a food technologist or other 
professional with knowledge of food manufacturing, but a restaurant chef. Darren Robertson is a co-owner and chef at Three Blue Ducks, a group of produce-driven eateries in NSW that have a strong ethical food focus and feature locally-sourced, organic and biodynamic produce. While he may be less well known than figures like Curtis Stone and Jamie Oliver, Robertson's appearances on MasterChef Australia, Ready Steady Cook and as co-author of The Three Blue Ducks cookbook mean that, for many, Robertson's 'ethical' credentials would be recognisable. Regardless of his broad recognisability as a more minor celebrity chef, however, Robertson's central positioning of the show serves once again as an authenticating device for Woolworths. Reflecting again the major supermarkets' increasing use of celebrity chefs in their advertising and branding in order to leverage their 'ethical capital', Robertson's chef credentials and his association with restaurant rather than massproduced food suggest another sleight of hand by Woolworths, an attempt to narrow the perceived gap between their industrialised mass produced food items and the more connected, authentic and artisanal relationship to food represented by restaurant (and home-cooked) cuisine.

\section{Conclusion: Bringing Home the (Ethical) Bacon}

As argued in this chapter, in recent years mainstream media have targeted a range of broad political and ethical issues in relation to industrial food production, the health impacts of processed foods, the treatment of livestock, the plight of farmers and the environmental impact of agri-business practices. Consumers have become increasingly concerned about the growing length and complexity of food chains so it is perhaps no surprise that modes of food television that not only seek to expose the realities behind food production but that also re-connect us to the provenance of food and the skills involved in cooking from scratch have become popular on primetime screens around the world. In the context of growing consumer awareness, Australian supermarkets have recently begun to actively intervene in the space of food ethics and politics, employing celebrity chefs, for example, to give an ethical gloss to their marketing campaigns as well as developing new ethical product lines. Key here is the desire to claim a market-based, moral high ground in a context where supermarkets are under mounting media pressure and public scrutiny in relation to their practices of sourcing, their treatment of and commitment to Australian producers, and their perceived anti-competitive practices. 
As shown, these interventions have moved well beyond the spin of advertising campaigns but have involved both Coles and Woolworths, the key majors in Australia, entering the fray of food TV, with the format Recipe to Riches seeing Woolworths move beyond the usual tricks and techniques of integrated advertising to becoming a key player in the show's narrative. Here the show's emphasis on taking us 'behind the scenes' of the branding, marketing and production of would-be supermarket products, hand made by ordinary Australians, cleverly appropriates both the revelatory techniques of the ethical consumption movement and the movement's concerns with returning us to connected foodways and artisanal skills. Paralleling other related techniques in commercial culture such as greenwashing and 'lite on'

forms of corporate social responsibility, ${ }^{5}$ Recipe to Riches thus represents a potent way to reconnect with consumers, authenticate supermarkets and gloss over the realities of global agri-business. While the show's format is hardly a riveting one, the increased sales and new customers associated with each product launch suggest the complex way in which commercial media today can be seen to shape and intervene in broader social and economic processes.

\section{Bibliography}

Barnett, C., Clarke, N., Cloke, P. and Malpass, A. (2005) The political ethics of consumerism, Consumer Policy Review. 15 (2): 45-51.

Coff, C. (2006) The Taste for Ethics: An Ethic of Food Consumption. Dordrecht, the Netherlands: Springer.

Cook, H. (2012) Milk wars leave sour taste in farmers' mouths. Sydney Morning Herald. 21 January, 1-4.

Davidson, H. (2013) Coles v Woolworths: palm oil scorecard reveals markedly different rankings. The Guardian. 13 November, 1-4.

de Solier, I. (2005) TV Dinners: Culinary Television, Education and Distinction, Continuum: Journal of Media \& Cultural Studies. 19 (4): 465-81.

Dixon, J. and Isaacs, B. (2013) There's certainly a lot of hurting out there: navigating the trolley of progress down the supermarket aisle, Agriculture and Human Values. 30, 2, 283-97.

Ferguson, S. (2011) A Bloody Business. abc.net.au. 30 May. 
Fielke SJ and Bardsley DK. (2012) South Australian Farmers’ Markets: Tools for Enhancing the Multifunctionality of Australian Agriculture. GeoJournal 78(5): 759-776.

Friedmann H. (2005) From Colonialism to Green Capitalism: Social Movements and Emergence of Food Regimes. New Directions in the Sociology of Global Development: Research in Rural Sociology and Development 11: 227-264.

Fyfe, M. and Millar, R. (2013b) Free to range or not, have supermarkets egg on their faces? The Age. 4 March, 1-2.

Goodman D. (2003) The Quality “Turn” and Alternative Food Practices: Reflections and Agenda. Journal of Rural Studies 19: 1-7.

Goodman, M.K., Maye, D. and Holloway, L. (2010) Ethical foodscapes?: premises, promises, and possibilities, Environment and Planning A. 42 (8): 1782-96.

Greenblat, E. (2013a) Coles Woolworths still in sights of ACCC despite new code of conduct. Sydney Morning Herald. 18 November : http://www.smh.com.au/business/retail/coles-woolworths-still-in-sights-of-acccdespite-new-code-of-conduct-20131118-2xq92.html\#ixzz3StymsLTh

Greenblat E. (2013b) Food Show Has the Right Ingredients for Woolies. The Sydney Morning Herald, 7 October: 27.

Guthrie J, Guthrie A and Lawson R (2006) Farmers’ Markets: The Small Business Counter-Revolution in Food Production and Retailing. British Food Journal 108(7): 560-573.

Humphery, K. (2008) Shelf Life: Supermarkets and the Changing Cultures of Consumption. Cambridge: Cambridge University Press.

Hickman, M. (2008) The campaign that changed the eating habits of a nation. The Independent. 28 February, 1-2.

Jackson S. (2013) Ratings Undercooked But Woolies Loves It. The Australian, 4 November: 25.

Janda M. (2010) Coles Sales Climb on MasterChef Bandwagon. ABC News, 26 July, http://www.abc.net.au/news/2010-07-26/coles-sales-climb-on-masterchefbandwagon/920014.

Keith S (2012) Coles, Woolworths, and the Local. Locale: The Australasian-Pacific Journal of Regional Food Studies 2: 47-81.

King, S. (2013) FactCheck: do Coles and Woolies control 80\% of the market? 7 July 2013. The Conversation, 6 August.

Lewis, S. (2011) Who's the reel deal? Heston Blumenthal, Gordon Ramsay and Jamie 
Oliver take on the villains of the fishing world. The Daily Mail. 5 January, 1-4.

Lewis, T. (2008), Smart Living: Lifestyle media and popular expertise, Peter Lang, New York.

Lewis, T. (2010) Branding, Celebritization and the Lifestyle Expert, Cultural Studies. 24 (4): 580-98.

Lewis, T. (2014) Lifestyle Media. In Maguire, J.S. and Matthews, J. (eds.) The Cultural Intermediaries Reader. SAGE. pp 134-144.

Lewis, T. and Huber, A (2015). A revolution in an eggcup? Supermarket wars, celebrity chefs, and ethical consumption, Food, Culture and Society, 18 (2): 289-308.

Lewis, T. and Potter, E. (eds.) (2011) Ethical Consumption: A Critical Introduction. Lewis, T. and Potter, E. (eds.). Routledge.

Martin, P. (2013) Independent MPs join forces to take on Woolworths, Coles over high market share. Sydney Morning Herald. 18 June, 1-1.

McIntyre P. (2012) Big Supermarkets on the Nose. The Australian Financial Review 30 April: 45.

Pollan M. (2006) The Omnivore's Dilemma: A Natural History of Four Meals. New York: Penguin.

Pollan M. (2008) In Defence of Food: An Eater's Manifesto. London: Penguin.

Richards C, Lawrence G and Burch D. (2011) Supermarkets and Agro-Industrial Foods: The Strategic Manufacturing of Consumer Trust. Food, Culture \& Society 14(1): 29-47.

Richards C, Lawrence G, Loong M and Burch D. (2012) A Toothless Chihuahua? The Australian Competition And Consumer Commission, Neoliberalism and Supermarket Power in Australia. Rural Society 21(3): 250-263.

Sinclair L. (2010) MasterChef Sparks Coles Sales Surge. The Australian, 21 June: 32. Spurgeon C. (2013) Regulating Integrated Advertising. In: McAllister MP and West E

(eds) The Routledge Companion to Advertising and Promotional Culture. New York: Routledge, 71-82.

Strange N. (1998) Perform, Educate, Entertain: Ingredients of the Cookery

Programme Genre. In: Geraghty C and Lusted D (eds) The Television Studies

Book. London: Arnold, 301-312.

Whyte, S. (2013) Woolworths to phase out all battery hen eggs. The Sydney Morning Herald. 4 October, 1-2.

Zappone, C. (2011) Local meat eaters turned off by Indonesian cattle scandal. Sydney Morning Herald. 8 June, 1-2. 


\footnotetext{
${ }^{1}$ See http://www.sbs.com.au/shows/gourmetfarmer/ and http://www.lifestyle.com.au/tv/paddock-toplate/.

${ }^{2}$ These issues, along with the matters related to the concentration of the market, have prompted ongoing investigations by the Australian Competition and Consumer Commission (ACCC), Australia's competition regulator (see Greenblatt 2013a). A critical appraisal of the ACCC's efficacy in dealing with concerns around Australia's supermarket duopoly and the concentration of power in the sector can be found in Richards et al. (2012).

${ }^{3}$ The RSPCA is the Royal Society for the Protection of Cruelty to Animals. The US equivalent is the ASPCA.

${ }^{4}$ From the opening titles of River Cottage - Spring (2008).

${ }^{5}$ The term greenwashing refers to when organisations that are not particularly environmentally sound nevertheless invest considerable time and effort in promoting the perception that their policies, products and practices are 'green'. The concept of corporate social responsibility, or corporate citizenship, refers to the notion that corporations have responsibility not only for the economic consequences of their activities, but also for potential social and environmental impacts.
} 